\title{
Post-cooling survival, growth and deformity rates in zebrafish embryos (Danio rerio)
}

\author{
Maria do Carmo Faria Paes ${ }^{1}$ and Laura Satiko Okada Nakaghi ${ }^{2}$ \\ Aquaculture Centre of São Paulo State University (CAUNESP), Jaboticabal, São Paulo, Brazil
}

Date submitted: 20.06.2017. Date revised: 11.08.2017. Date accepted: 07.11.2017

\section{Summary}

This study investigated and analysed survival, growth and macro- and microscopic damage during the development of zebrafish embryos up to the adult stage after undergoing cooling. The embryos at $50 \%$ epiboly stage were selected, submerged in cryoprotectant solution of methanol and sucrose, cooled gradually to $0 \pm 2{ }^{\circ} \mathrm{C}$ temperature, and divided into two groups with different storage times (6 and $18 \mathrm{~h})$. Subsequently, the embryos were reheated, rehydrated and incubated normally. The experiment lasted 5 months and, from hatching onward, the larvae were examined, collected and processed at pre-established time intervals. The hatching rate was significantly higher for the larvae stored for 18 $\mathrm{h}$ compared with the 6-h group. However, embryos from this group gave rise to a larger number of malformations, and these were much more severe compared with those in the $6 \mathrm{~h}$ group, which led to a higher mortality in the long term. Regarding larval length, the animals of the $6 \mathrm{~h}$ group had higher mean total length compared with the $18 \mathrm{~h}$ group, but both treatments were inferior to the control. Numerous macro- and microscopic malformations were observed and, in both treatments, only the morphologically normal individuals were able to develop to the adult stage, with organ development similar to the control, except for the gonads that were still undifferentiated in treated animals.

Keywords: Fish embryos, Low temperature, Malformation, Microscopy, Morphology

\section{Introduction}

Zebrafish is the most used species in embryo cryopreservation research in the world (GODOY et al., 2012). This small fish, with sexual dimorphism and split spawning, is easy to breed, reaching sexual maturity at approximately $23 \mathrm{~mm}$ (Dammski et al., 2011).

The fish embryos exhibit some characteristics that hamper their freezing and/or vitrification. They have characteristically large egg yolk, low surface/volume ratio, large cells. Each embryo compartment has possibly different osmotic properties, semi-permeable membranes surrounding the embryo and high sensitivity at low temperatures (Rall, 1993; Rawson \&

\footnotetext{
${ }^{1}$ All correspondence to: Maria do Carmo Faria Paes. Department of Animal Morphology and Physiology, São Paulo State University, Campus Jaboticabal, São Paulo, Brazil. Access way Professor Paulo Donato Castellane, S/N, Jaboticabal-SP, CEP 14884-900, Brazil. Tel:/Fax: +55 1632092654 (ext. 232). E-mail: maria.paes@fcav.unesp.br

${ }^{2}$ Aquaculture Centre of São Paulo State University

(CAUNESP), Jaboticabal, São Paulo, Brazil.
}

Zhang, 2005; Ninhaus-Silveira et al., 2008). Currently, the cooling technique has given the best results for these embryos as there is no formation of ice crystals in the cells because temperature is not critical (Ahammad et al., 2003).

There are several applications for cooling fish embryos, among these, optimizing incubator use, transporting embryos to distant places, rescuing spawnings from pollutant threats, minimizing asynchronous maturation of gametes, improving knowledge on embryo resistance to cold, and providing a basis for freezing studies (Miliorini et al., 2002, Fornari et al., 2012).

Hatching and survival rates normally are the only indicators used to evaluate the success of the cooling technique of fish embryos (Desai et al., 2011). Furthermore, it is known that low temperatures affect larvae somehow, but there are few studies showing data on possible anomalies or proving that cryopreserved larvae can develop up to the sexual maturation phase (Paes et al., 2014).

Therefore, this study aims at monitoring the development of Danio rerio embryos, submitted to cooling, and reaching full length for sexually mature fish, by 
analysing hatching, growth and possible structural and ultrastructural damage caused by this process, to improve existing cryopreservation protocols, alleviate problems and provide basic knowledge for future studies.

\section{Materials and methods}

Danio rerio embryos from the spawnings of approximately 60 adult couples were kept in three 100 litre aquariums (20 couples in each aquarium) at controlled $\pm 28^{\circ} \mathrm{C}$ temperature with $12 \mathrm{~h}$ photoperiod (light/dark). Breeders were fed three times daily with commercial TetraMin ${ }^{\circledR}$ flakes and freshly hatched Artemia. Bottles containing stones for fishkeeping were added to the aquariums as spawning substrate. Every morning, the substrates with the embryos were removed to examine and collect the embryos.

Ten spawnings, each pooling approximately 400 embryos in the $50 \%$ epiboly phase, were used for each cooling treatment and control (no cooling). These embryos were packed in vacutainer tubes containing a cryoprotectant solution consisting of $1 \mathrm{M}$ methanol + $0.1 \mathrm{M}$ sucrose, cooled gradually to reach $0 \pm 2^{\circ} \mathrm{C}$ and stored in a refrigerator for 6 -h or 18 -h periods.

After the proposed times, the tubes were placed in a water bath at room temperature for $15 \mathrm{~min}$. The embryos were rehydrated as follows: $10 \mathrm{~min}$ in $90 \%$ cryoprotectant solution $+10 \%$ incubation water (IW); 10 min in $70 \%$ cryoprotectant solution $+30 \%$ IW, 10 min in $40 \%$ cryoprotectant solution $+60 \%$ IW, and $10 \mathrm{~min}$ in $15 \%$ cryoprotectant solution $+85 \%$ IW. Finally, the embryos were washed three times with IW only and transferred to experimental incubators with continuous aeration at $\pm 28^{\circ} \mathrm{C}$ to follow development.

\section{Hatching and deformities}

Hatching and deformity rates were determined for all spawnings after at least $80 \%$ of the larvae had already ruptured the chorion over the 5-month period of the experiment. Larvae that presented any type of anomaly were considered deformed.

The rates were calculated with in vivo larvae using a stereomicroscope, as follows:

$$
\begin{aligned}
& \text { hatching rate }(\%) \text { : (hatched larvae } \div \text { total number of } \\
& \text { embryos that were cryopreserved }) \times 100 \\
& \text { deformity rate }(\%) \text { : (deformed larvae } \div \text { number of } \\
& \text { hatched larvae) } \times 100 \text {. }
\end{aligned}
$$

\section{Sampling, growth, and stereomicroscopy}

The larvae from the two treatments and control were kept under the ideal breeding condtions for the species. After opening of the mouth (approximately 3 to 5 post- hatching days), they were fed newly hatched Artemia nauplii, and from 8 post-hatching days, besides the $A$. nauplii, commercial TetraMin ${ }^{\circledR}$ flakes were offered two to three times daily. The ontogenetic development was followed until the individuals reached approximately $23 \mathrm{~mm}$ at the following times hatching, $2^{\circ}, 3^{\circ}, 4^{\circ}, 5^{\circ}, 6^{\circ}$, $7^{\circ}, 10^{\circ}, 13^{\circ}, 16^{\circ}, 20^{\circ}, 24^{\circ}, 28^{\circ}, 35^{\circ}, 45^{\circ}, 65^{\circ}$ post-hatching days (PHD).

Total length was determined on 10 larvae from each sampling time. The larvae were anesthetized with benzocaine and photomicrographed using a LEICA MZ8 stereomicroscope, coupled to the LEICA DFC 295 digital camera and measured using the LAS image analyser V 5.8 software. From the $20^{\circ}$ PHD, the measurements were taken by a digital pachymeter.

\section{Light microscopy}

The samples were processed following two histological inclusion techniques with different stains. For all techniques, three larvae from each sampling time were preserved in Karnovsky solution (2.5\% glutaraldehyde $+2.5 \%$ paraformaldehyde) for $24 \mathrm{~h}$ and washed in 0.1 $\mathrm{M}$ phosphate buffer, $\mathrm{pH}$ 7.4. The next sections describe the steps that followed:

\section{Historesin}

The samples were dehydrated in $80 \%$ alcohol solution for $24 \mathrm{~h}$, followed by two washings in $90 \%$ and $100 \%$ alcohol for $30 \mathrm{~min}$. The Leica ${ }^{\circledR}$ historesin kit was used according to the instructions: pre-infiltration in glycolmethacrylate (GMA) + ethanol (1: 1) for $4 \mathrm{~h}$; the infiltration stage (GMA) for $16 \mathrm{~h}$, followed by inclusion in GMA + hardener, with larvae positioned in a lateral decubitus position. The samples were incubated for resin polymerization at $60^{\circ} \mathrm{C}$ for $24 \mathrm{~h}$. The $2-\mu \mathrm{m}$ histological sections were prepared using glass blades.

The assembled slides were stained with hematoxylin-floxin (Tolosa et al., 2003), microphotographed using the Leica DM 2500 photomicroscope coupled to the LEICA DFC 295 digital camera and analysed using the LAS image analyser V 5.8 software.

\section{Paraplast}

The samples were kept in each of the dehydration solutions (80, 90, 95 and $100 \%$ alcohol) for $5 \mathrm{~min}$, followed by diaphanization (three baths in xylol) and the paraplast (Merck) infiltration steps for $20 \mathrm{~min}$ and inclusion. The head and tail of the larger animals were previously removed while keeping the celoma cavity intact as ossification hampers microtome processing and cutting. The fish were included in the lateral decubitus position. The $5-\mu \mathrm{m}$ thick histological sections were assembled in slides, stained with 


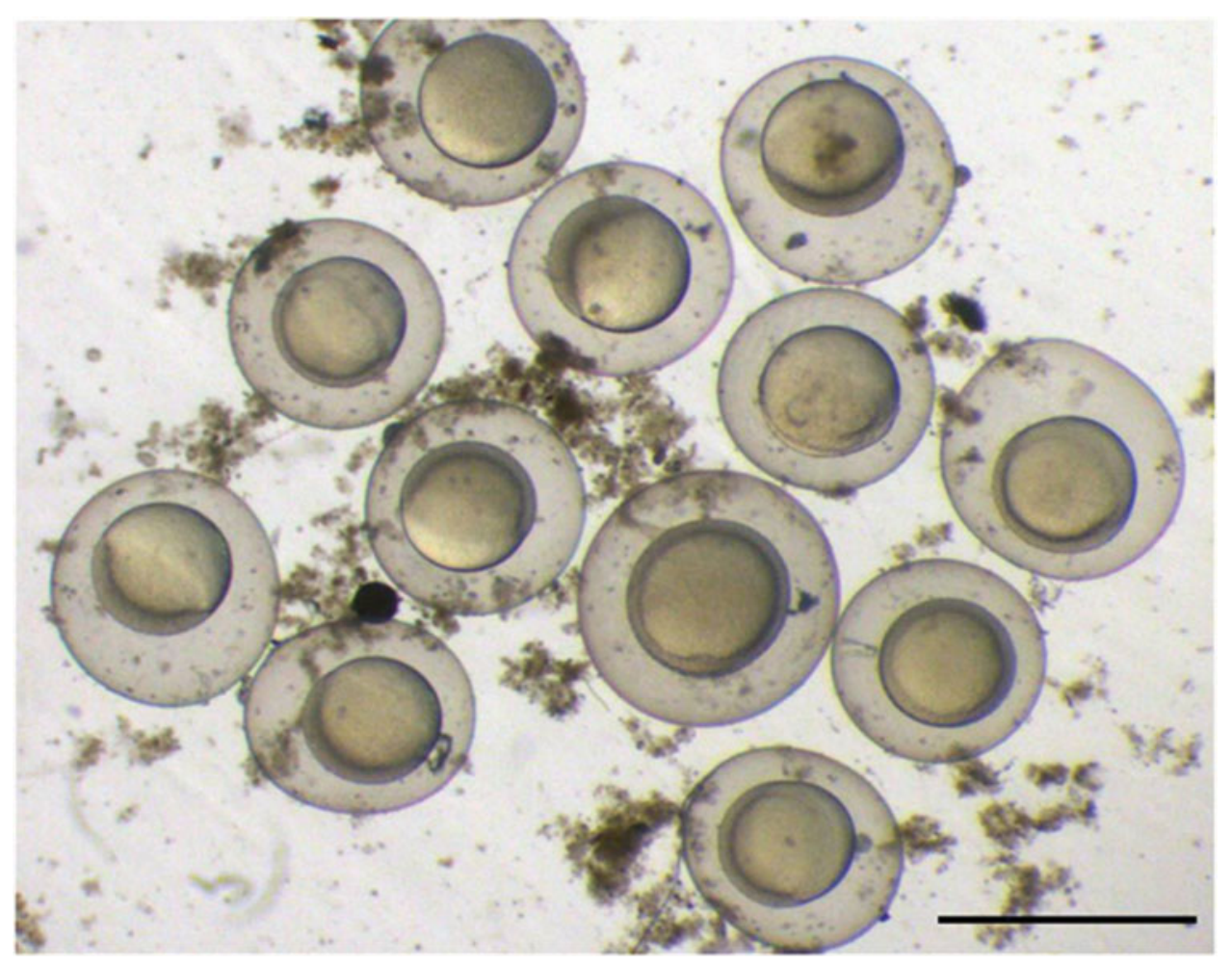

Figure 1 Photomicrograph of different $D$. rerio egg sizes. (Bar represents $0.5 \mathrm{~mm}$.)

haematoxylin-eosin (TOLOSA et al., 2003), photomicrographed in the Leica DM 2500 photomicroscope coupled to the LEICA DFC 295 digital camera and analysed by the LAS image analyser V 5.8 software.

\section{Transmission electron microscopy (TEM)}

The samples were submerged in $2 \%$ osmium tetroxide buffer for $2 \mathrm{~h}$, followed by dehydration in increasing ethanol concentrations $(30,50,70,80,90,95$ and $100 \%)$. Infiltration was performed with resin and acetone and the inclusion, in resin. Semi-thin $0.5-\mu \mathrm{m}$ sections were prepared using a glass blade microtome, and the slides were stained with $1 \%$ toluidine blue in saturated boric acid. The best cuts were used for histological analysis while also choosing the areas of interest for the ultrathin $60-\mathrm{nm}$ sections that were prepared using a diamond blade, stained, observed and electromicrographed in a JEO-JEM 100CX II transmission electron microscope (TEM).

\section{Water quality}

The experimental broodstock aquariums and larval incubators were cleaned daily to maintain the ideal environmental conditions for the normal development of broods and embryos/larvae. The following physicalchemical characteristics of the water were recorded: temperature and dissolved oxygen $(\mathrm{mg} / \mathrm{l})$, by YSI 550
A equipment, $\mathrm{pH}$, by YSI 63 equipment and ammonia $(\mu \mathrm{g} / 1)$ by Goltermann et al. (1978) method.

\section{Results}

\section{Hatching, deformity and growth rates}

Zebrafish reproduction is induced by the brightness of the morning sun and occurs in steps while a Danio rerio adult female can spawn several times within a month. Spawning was estimated to have occurred between 5 and 6 o'clock in the morning. In the control group, hatching started between 50 and $55 \mathrm{~h}$ after the estimated fertilization time for all spawnings, at $28 \pm$ $1^{\circ} \mathrm{C}$ average temperature. However, the cryopreserved groups took about 5 to $20 \mathrm{~h}$ longer than the control to initiate hatching. It is noteworthy that development between spawnings from different couples, even for embryos selected at exactly the same stage, was not simultaneous. Egg diameter varied considerably (Fig. 1), ranging from 0.522 to $0.805 \mathrm{~mm}$. Sampling for microscopic processing started with the first larvae that hatched, but the hatching rate was calculated after at least $80 \%$ of the larvae were already chorion free and had a clear heartbeat (day 2 post-hatching). It is important to define when the hatch rate was calculated in cryopreservation studies, as this is a slow process, and we observed considerable mortality from the 
Table 1 Mean hatching and deformity values and standard deviation

\begin{tabular}{llc}
\hline Storage time & Hatching $(\%)$ & Deformity $(\%)$ \\
\hline Control & $67.50 \pm 2.52^{a}$ & $2.40 \pm 0.07^{a}$ \\
$18 \mathrm{~h}$ & $39.80 \pm 6.05^{b}$ & $77.8 \pm 3.47^{b}$ \\
$6 \mathrm{~h}$ & $18.75 \pm 6.25^{c}$ & $10.2 \pm 5.54^{c}$ \\
\hline
\end{tabular}

$a, b, c$ Different letters differ significantly from each other (Tukey $P<0.05$ ).

Table 2 Mean total larval length $(\mathrm{mm})$ and standard deviation for the control and cryopreserved groups after 18 and $6 \mathrm{~h}$ of storage

\begin{tabular}{lrrr}
\hline & $18 \mathrm{~h}$ & $6 \mathrm{~h}$ & \multicolumn{1}{c}{ Control } \\
\hline Hatching & $2.39 \pm 0.417^{a}$ & $2.51 \pm 0.153^{a}$ & $1.89 \pm 0.163^{b}$ \\
2 PHD & $2.05 \pm 0.185^{a}$ & $3.08 \pm 0.094^{b}$ & $3.08 \pm 0.125^{b}$ \\
3 PHD & $2.15 \pm 0.056^{a}$ & $2.89 \pm 0.530^{b}$ & $3.37 \pm 0.249^{b}$ \\
4 PHD & $2.08 \pm 0.239^{a}$ & $2.96 \pm 0.530^{b}$ & $3.36 \pm 0.274^{b}$ \\
5 PHD & $1.84 \pm 0.554^{a}$ & $2.57 \pm 0.481^{b}$ & $3.27 \pm 0.063^{c}$ \\
6 PHD & $2.07 \pm 0.783^{a}$ & $3.45 \pm 0.236^{b}$ & $3.16 \pm 0.156^{b}$ \\
7 PHD & $2.06 \pm 0.345^{a}$ & $3.29 \pm 0.190^{b}$ & $3.41 \pm 0.035^{b}$ \\
10 PHD & $3.38 \pm 0.329^{a}$ & $3.27 \pm 0.156^{a}$ & $3.67 \pm 0.142^{a}$ \\
13 PHD & $3.53 \pm 0.217^{a}$ & $3.56 \pm 0.148^{a}$ & $3.19 \pm 0.188^{a}$ \\
16 PHD & $4.34 \pm 0.185^{a}$ & $4.29 \pm 0.455^{a}$ & $5.18 \pm 0.698^{b}$ \\
20 PHD & $4.71 \pm 0.170^{a}$ & $5.45 \pm 0.294^{b}$ & $6.30 \pm 1.661^{c}$ \\
24 PHD & $6.63 \pm 0.262^{a}$ & $7.22 \pm 0.211^{b}$ & $9.67 \pm 1.458^{c}$ \\
28 PHD & $8.10 \pm 1.049^{a}$ & $11.75 \pm 1.760^{b}$ & $13.45 \pm 0.926^{c}$ \\
35 PHD & $9.25 \pm 1.022^{a}$ & $10.30 \pm 2.060^{b}$ & $16.61 \pm 0.446^{c}$ \\
45 PHD & $13.90 \pm 1.474^{a}$ & $15.55 \pm 1.650^{b}$ & $24.12 \pm 0.701^{c}$ \\
65 PHD & $23.40 \pm 1.480^{a}$ & $26.80 \pm 2.350^{b}$ & $32.00 \pm 2.669^{c}$ \\
\hline
\end{tabular}

$a, b, c$ Different letters differ significantly from each other (Tukey test $P<0.05$ ).

PHD, post-hatching days.

beginning until the end of hatching, when all larvae were already free.

During hatching, the larvae that had any anomaly were also counted. The comparison of the two treatments showed a higher hatching rate for $18 \mathrm{~h}$ compared with $6 \mathrm{~h}$ (Table 1). However, most of the larvae of the $18 \mathrm{~h}$ treatment had some deformity (Table 1), which compromised their survival over time.

At hatching, cryopreserved larvae were longer compared with those of the control group (Table 2). This result can be explained by the tail anomalies observed in the cryopreserved larvae that rendered the rupture movements to break the chorion more difficult and, therefore, because they took a longer time to hatch (from 5 to $20 \mathrm{~h}$ longer, as previously mentioned), they hatched at a more developed stage (Fig. 2).

During development, $6 \mathrm{~h}$ larvae were generally longer than the $18 \mathrm{~h}$ larvae, most of which did not have a developed/formed tail (Fig. 2C, E). However, from
16 PHD onward, the two treatments had significantly smaller animals compared with control, indicating that the cryopreservation may have affected larval length.

\section{Stereomicroscopy}

There were malformations in all groups. However, deformities were much more severe and more frequent in the group submitted to 18 -h cooling. It was observed that deformed larvae had low swimming capacity, and often remaining at the bottom of the incubator.

The main deformities observed in the stereomicroscope were lordosis, kyphosis, scoliosis, tail curvature, coiled tail, short or absent tail, yolk alterations, edema in the pericardial and abdominal regions, head and eye malformation (Figs 3 and 4).

The occurrence of deformities observed in each group is shown in Table 3.

\section{Light microscopy and transmission electron microscopy}

In the stereomicroscope, cell and tissue abnormalities were observed in deformed larvae of both treatments, but the deformity rate was higher for the 18-h treatment. Furthermore, the cryopreserved larvae that had no macroscopic or microscopic alterations were able to develop normally. In both treatments, notochord malformations were associated with alterations in skeletal striated muscles, such as separation of muscle fibres, atrophied musculature or shortened muscle fibres, and fibrosis (large amount of loose intramuscular connective tissue) (Fig. 5A-C). There were also malformations in the hyaline cartilage, which had large numbers of chondrocytes presenting cell death with an irregular and fragmented nuclear membrane (Fig. 6D-F). Regarding the gonads, the formation of a gonadal cord consisting especially of somatic cells and some primordial germ cells, the gonocytes, was observed from 2PHD, 4PHD and 6PHD onwards in the control, $6 \mathrm{~h}$ and $18 \mathrm{~h}$ treatments, respectively. This gonadal cord was located in the coelom region, above the intestine and below the dorsal musculature, in which pigmentary cells were present as dark granules, aggregated to the prolongations of the gonadal mesentery region (Fig. 7E). The comparison of cryopreserved and control animals of the same body size showed that the latter had well formed gonads (Fig. 7F), while in the cryopreserved the gonads were undifferentiated, with abundant connective tissue and without definite cells in the ovaries or testicles.

Moreover, some abnormalities were observed only in the larvae of the $18 \mathrm{~h}$ treatment. The larvae had erythrocytes with cytoplasmic vacuolization 

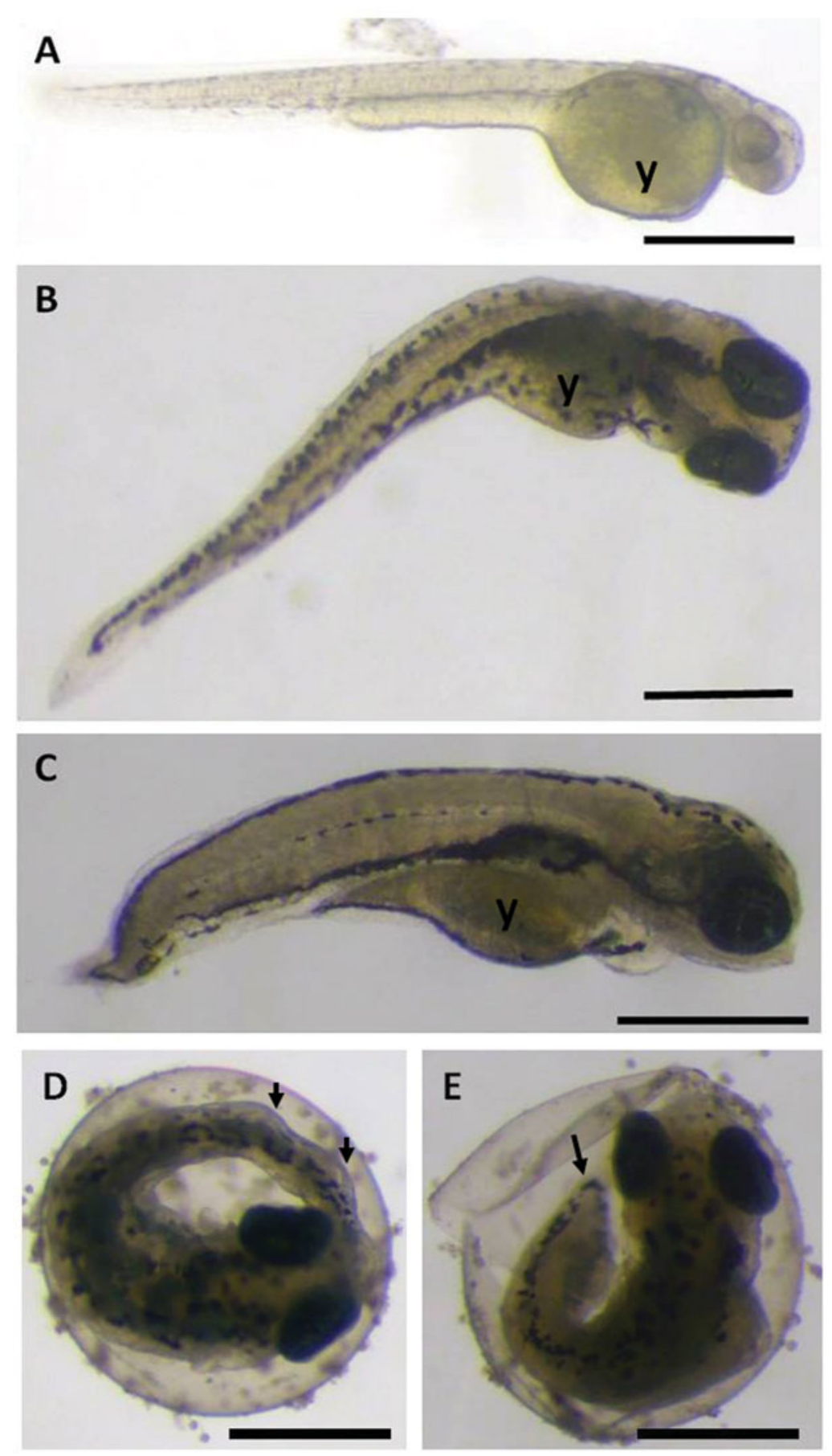

Figure 2 Photomicrograph of $D$. rerio larvae. (A) Hatched larva from the control group. (B) Hatched larva from the cryopreserved group $(6 \mathrm{~h})$. (C) Hatched larva from the cryopreserved group $(18 \mathrm{~h})$. (D) Comparison between pre-hatched larvae from the cryopreserved and control groups, observe the curved tail (arrow) (6 h). (E) Comparison between pre-hatched larvae from the cryopreserved and control groups, observe the short tail (arrow) and broken chorion (18 h). (y: yolk sac) (Bars represent $0.5 \mathrm{~mm}$ ).

(Fig. 6A-C), cells of the forming nervous tissue presented degeneration of the cytoplasmic membrane (apoptosis) (Fig. 6D-F), and a large amount of mitochondria present in intestinal epithelial cells displayed had disarranged mitochondrial ridges and abnormal increase in cytoplasmic volume (Fig. $7 A-D$ ).

\section{Water quality}

The mean values of water quality parameters of the experimental incubators and breeding aquariums were $28 \pm 1^{\circ} \mathrm{C}$ temperature, $7.2 \mathrm{pH}, 48.2 \mu \mathrm{g} / 1$ ammonia, and $5.22 \pm 1.9 \mathrm{mg} / 1$ dissolved oxygen. The parameters 

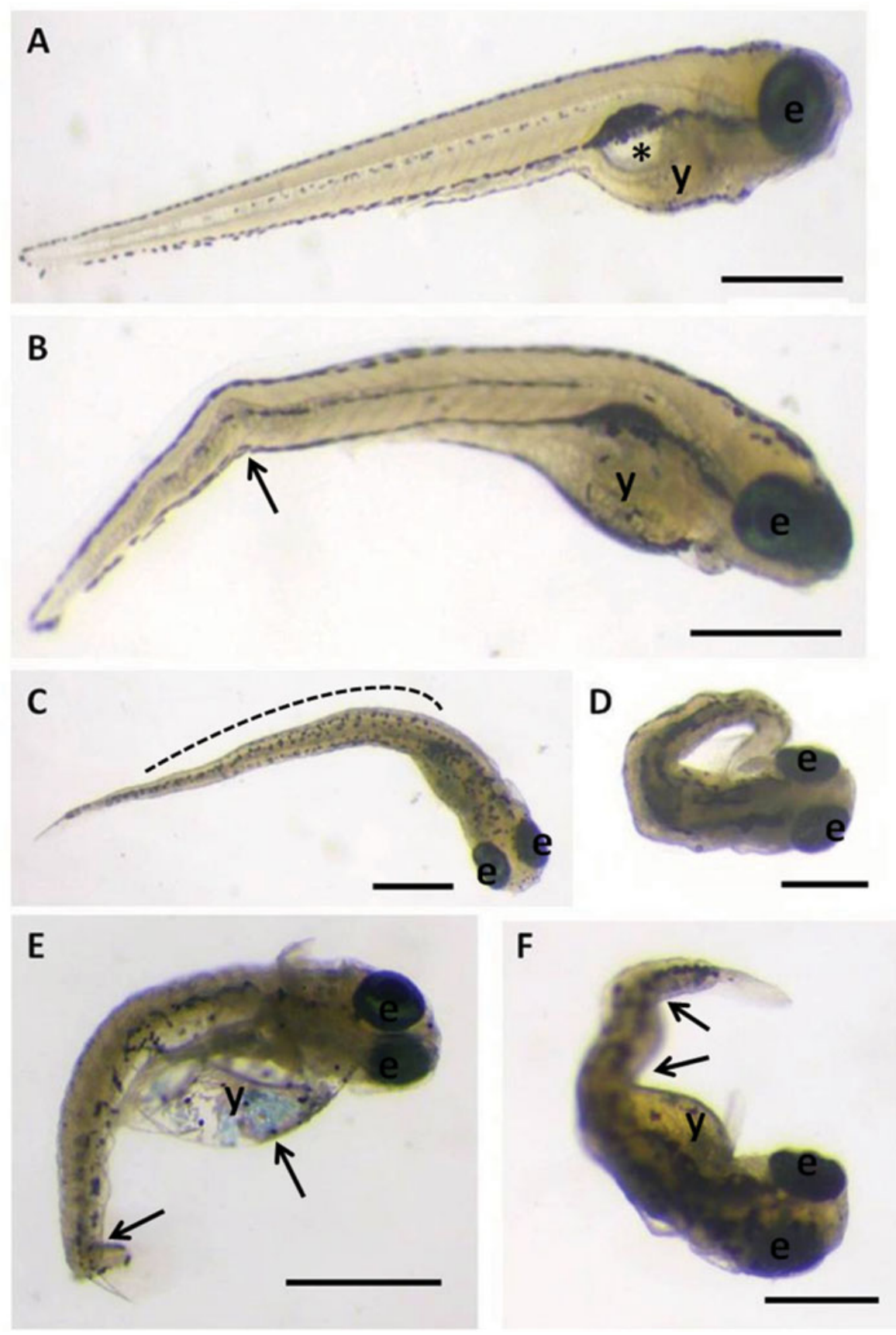

Figure 3 Photomicrograph of $D$. rerio larvae. (A) Larva from the control group (3PHD). (B) Larva with curved tail (arrow) and kyphosis (6 h, 3PHD). (C) Larva with scoliosis (6 h, 3PHD). (D) Larva with coiled tail (18 h, 5PHD). (E) Larva with curved tail, edema in the abdominal region, altered yolk (arrows) and curved spine (18 h, 5PHD). (F) Larva with spinal malformation and curved tail (arrows) (18 h, 4PHD). (y: yolk sac; e: eye; *: swimming bladder) (Bars represent $0.5 \mathrm{~mm}$ ).

analysed were within the expected range for the species (Dammski et al., 2011).

\section{Discussion}

The photoperiod strongly influences zebrafish reproduction. In general, ovulation occurs shortly before dawn and spawning begins in the first hour of daylight (Dammski et al., 2011). Embryonic development of zebrafish is slow, and from fertilization, hatching can take between 48 and $72 \mathrm{~h}$ at approximately $28^{\circ} \mathrm{C}$ (Kimmel et al., 1995; Dammski et al., 2011). In addition to genetic factors, environmental conditions and egg size may influence developmental speed (Leme dos Santos \& Azoubel, 1996) and, in the present study, egg 

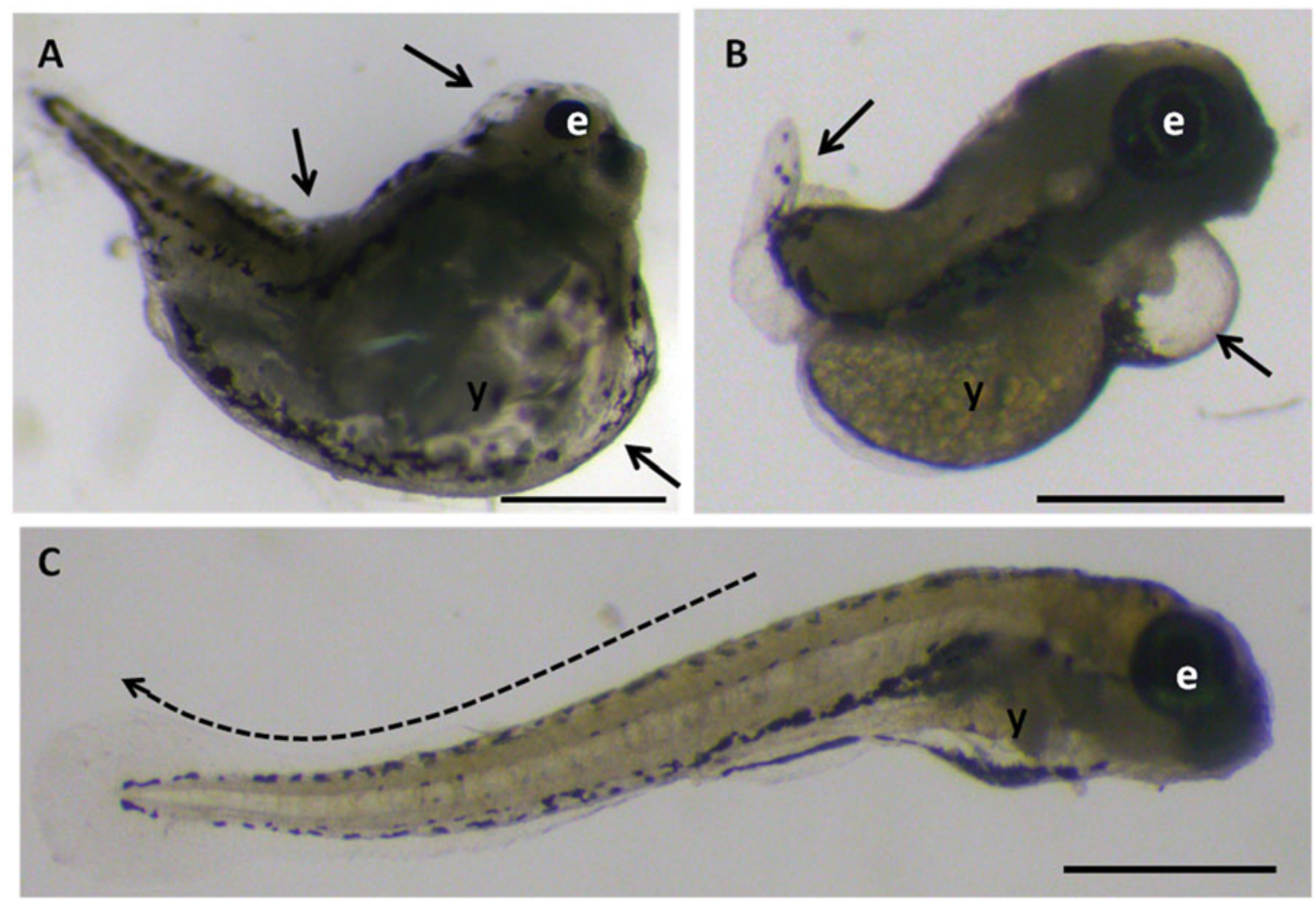

Figure 4 Photomicrograph of $D$. rerio larvae. $(A)$ Larvae with spinal malformation, altered yolk, abdominal edema, cephalic malformation and undersized eyes (arrows) (18 h, 5PHD). (B) Larvae with edema in the cardiac region and undeveloped tail (arrows) (18 h, 6PHD). (C) Larva with lordosis (dotted arrow) and small oedema in the abdominal region (6 h, 5PHD) (y: yolk; e: eye) (Bars represent $0.5 \mathrm{~mm}$ ).

Table 3 Types of deformities observed in the stereomicroscope and their respective occurrence in each treatment and control

\begin{tabular}{llll}
\hline Deformity type & $18 \mathrm{~h}$ & $6 \mathrm{~h}$ & Control \\
\hline Lordosis & + & + & \\
Kyphosis & + & + & - \\
Scoliosis & + & + & - \\
Curved tail & + & + & + \\
Coiled tail & + & - & - \\
Absent/short tail & + & + & - \\
Altered yolk & + & + & - \\
Cardiac edema & + & + & - \\
Abdominal edema & + & + & - \\
Cephalic malformation & + & - & - \\
Eye malformation & + & - & - \\
\hline
\end{tabular}

$+/-$, Plus and minus signs indicate deformity presence and absence, respectively.

diameter varied considerably. This fact is common to several teleost species while asynchrony occurs even within the same spawning (Nakatani et al., 2001).

Currently, the cooling technique has had the best results (Ahammad et al., 2003), but damage/malformation is still common in post-cooling embryos (Neves et al., 2014; Digmayer, 2010; Paes et al., 2014).
Considering the time of exposure to cold, which is another important factor that should be considered in cryopreservation protocols, we chose to compare larval damage caused by 6 or $18 \mathrm{~h}$ of cold storage. The choice of storage times was determined based on a previous study and also the research by Desai et al. (2015). Ahammad et al. (2003) studied the common carp (Cyprinus carpio) and reported that the survival rate tends to decrease as the storage period increases. Paes et al. (2014) investigated Brycon orbignyanus and demonstrated that for a storage time increase from 6 to $10 \mathrm{~h}$, mean hatchability values were halved. The present study has also shown that storage period negatively influenced zebrafish size, deformity index, and long-term survival.

It is essential that fish embryos can support the temperature reduction required by the cooling process. However, as already mentioned, cold can harm cells and/or tissues due to thermal shock and rapid cooling, or even slow cooling, for which damage is commonly manifested after long periods of exposure to low temperatures (Morris \& Watson, 1984 cited by Lopes et al., 2014).

The $18 \mathrm{~h}$ treatment, despite having a higher hatching rate, also had a larger number of more severely 

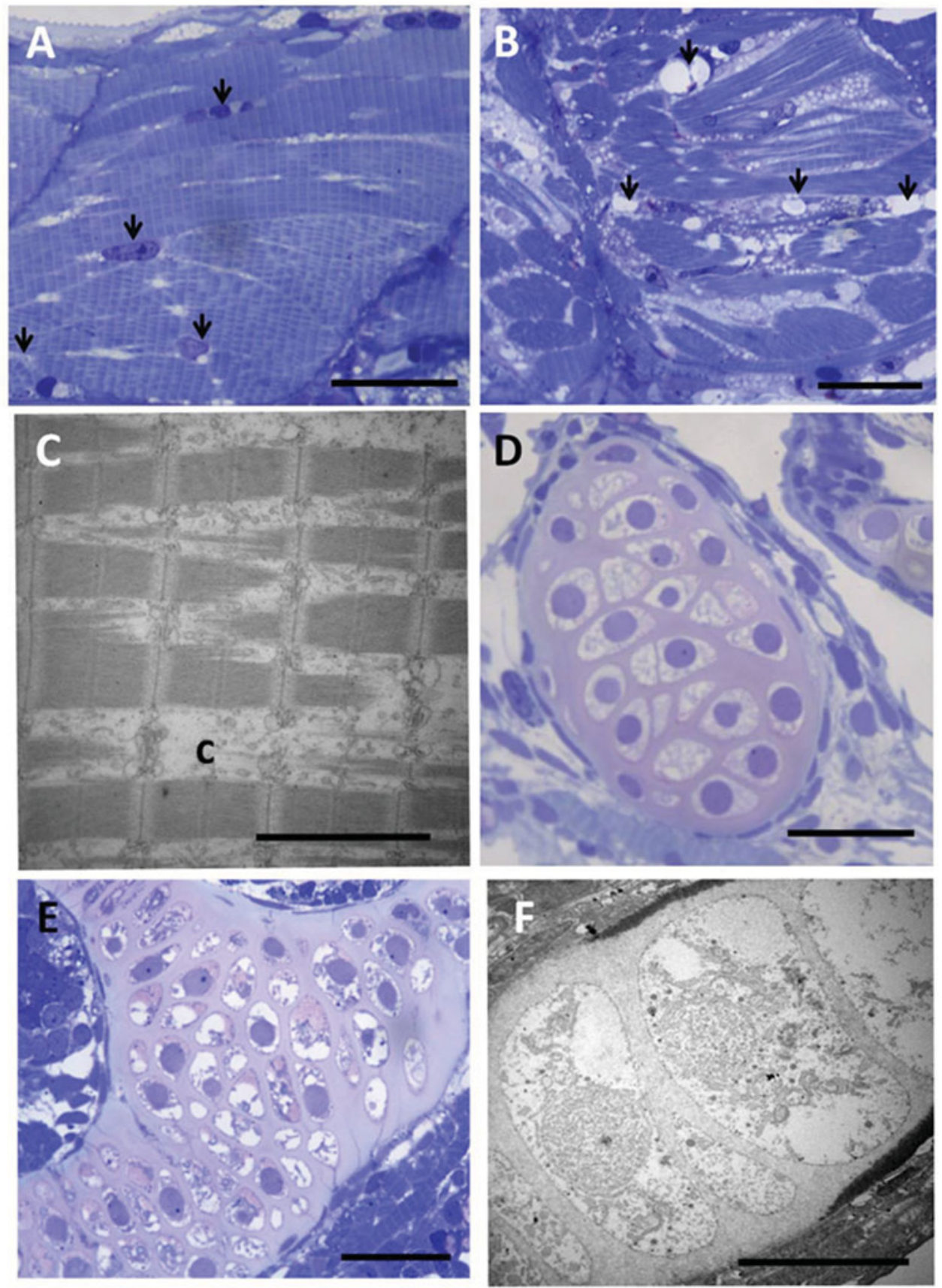

Figure 5 Photomicrograph $(A, B, D, E)$ and transmission electron micrograph $(C, F)$ of $D$. rerio larvae. $(A)$ Skeletal striated muscle with normal appearance (arrows: peripheral nuclei of muscle fibres - control, 2PHD). (B) Skeletal striated muscle showing some vacuoles (arrows), excessive loose connective tissue between muscle fibres $\left(^{*}\right)$ appearing flaccid and disorganized $(18 \mathrm{~h}$, hatching). (C) Skeletal striated muscle with short muscle fibres and fairly loose connective tissue present (C) (6 h, 5PHD). (D) Normal-looking hyaline cartilage (control, 3PHD). (E) Hyaline cartilage with altered chondrocytes in the medium extracellular matrix (18 h, 4PHD). (F) Hyaline cartilage highlighting chondrocytes with disorganized nucleus and non-integral nuclear membrane (18 h, 4PHD) (Col: Toluidine blue) (Bars represent $20 \mu \mathrm{m})$.

deformed larvae, which led to a high mortality rate during development. The deformed larvae had compromised swimming ability and often remained at the bottom of the incubator. Swimming activity is one of the most important behavioural changes as it is an indicator of the internal status of the animal (Little et al., 1993). The constant muscular requirement for swimming movements may be one of the causes of deformation in the spine and tail regions (Sakamoto \& Yone, 1978, cited by Nagamatsu, 2013). 

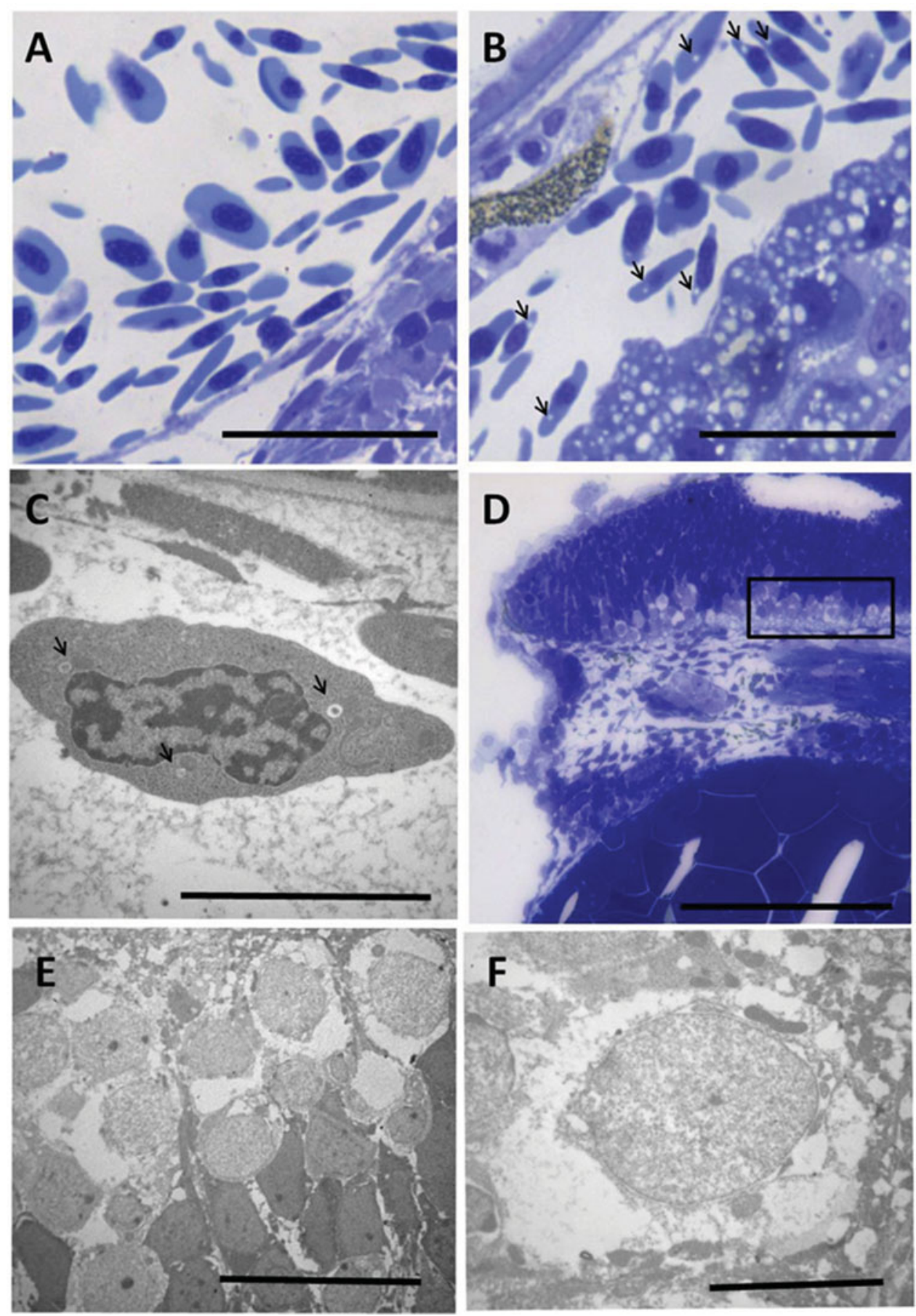

Figure 6 Photomicrographs $(A, B, D)$ and transmission electron micrographs $(C, E, F)$ of $D$. rerio larvae. $(A)$ Normal erythrocytes (control, 3PHD). (B, C) Presence of vacuoles in the erythrocyte cytoplasm (arrows) (18 h, 2PHD). (D) Head evidencing the region (square) of forming nervous tissue in which cells with degenerated cytoplasmic membrane (18 h, hatching) were found. (E, F) cytoplasmic degeneration/degenerate cytoplasmic membrane cells (18 h, hatching) ( ${ }^{*}$ : nucleus) (Col: Toluidine blue) (Bars: $A$, $B: 20 \mu \mathrm{m} ; C, F: 10 \mu \mathrm{m} ; D: 50 \mu \mathrm{m}$; and $E: 30 \mu \mathrm{m})$.

Poor formation of the spine and tail, as well as of the elements that make up the skeletal structure as a whole, that is, skeletal striated musculature, cartilage, and notochord, compromise larval survival. These anomalies are directly related to body balance and orientation in the water column, affecting the ability to escape, feed predation and swimming capacity in the early stages of development (Pinder \& Gozlan, 2004).

Among other deformities present in both treatments, we cite the cardiac and abdominal oedema in the larvae 

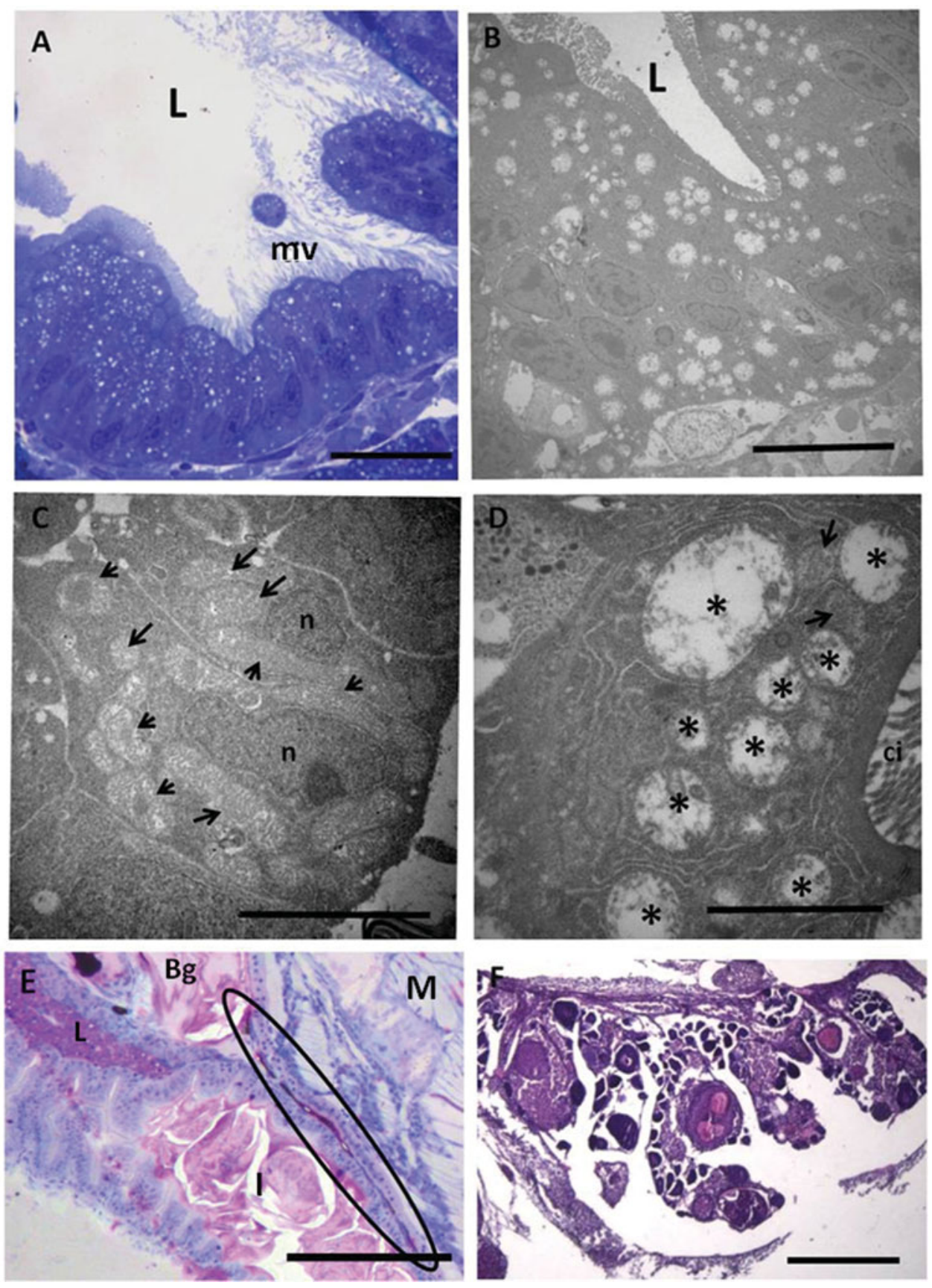

Figure 7 Photomicrographs $(A, E, F)$ and transmission electron micrographs $(B-D)$ of $D$. rerio larvae and adults. $(A, B)$ Intestinal epithelium showing enterocytes with large amount of altered mitochondria (18 h, 4PHD). (C) Enterocytes showing mitochondria with normal appearance (arrows) (control, 3PHD). (D) Enterocyte showing mitochondria with increased cytoplasmic volume $\left(^{*}\right)$ and normal mitochondria (arrows) (18 h, 4PHD). (E) Formation of the gonadal cord (circle) (6 h, 6PHD). $(F)$ Developed ovary evidencing oocytes at different maturation stages (control, 45PHD). (L: organ light, mv: microvilli, n: nucleus, L: liver, M: musculature, I: intestine, Bg: gas bladder.) (A: Toluidine blue, $E$ : haematoxylin-floxin, $F$ : haematoxylineosin.) (Bars represent: $A, B-20 \mu \mathrm{m} ; C-15 \mu \mathrm{m} ; D 10 \mu \mathrm{m} ; E-200 \mu \mathrm{m} ; F-500 \mu \mathrm{m}$.)

that were submitted to cooling. Oedema in fish larvae are commonly cited in many studies dealing with exposure to toxicants in water, environmental changes and nutrient deficiency as well (Costa, 2015; Fernandes, 2016; Stevanato, 2016). Oedema formation is generally characterized by an increase in metabolism, and may be caused by increased pressure, temperature fluctuation (Stevanato, 2016) and/or by subcutaneous haemorrhages, that is, blood stops circulating leading to erythrocyte accumulation (Walker \& Peterson, 
1991). In embryos, the oedemas usually occur in the abdominal, caudal regions, eyes and central nervous system (Leatherland \& Woo, 1998). One of the causes of cardiac oedema formation is the falling cardiac output due to myocardial failure (Coelho, 2014).

It was found that cryopreservation and exposure time to the cold affected the length of the animals throughout development. Elonen et al. (1998) suggest that the reduction in larval length may be related to the formation of oedema, because the pressure exerted on the blood vessels impedes blood circulation, leading to decreasing nutrient absorption by the body.

Erythrocytes with a predominantly elliptical-shaped nucleus, centrally located and densely basophilic heterochromatin were observed in the larvae of all treatments and control. However, small vacuoles were observed in the cytoplasm of few larvae of the $18 \mathrm{~h}$ group. According to Campbell (2004), areas of the cytoplasm with vacuolated and/or pale regions may be considered common in fish erythrocytes and have been associated with the degeneration of cellular organelles.

As for the damage found only in the $18 \mathrm{~h}$ group, we cite the degenerating nerve tissue cells. According to Godoy et al. (2012), one of the main typs of damage caused by the cooling is the homeostatic balance disorder, resulting from the different effects of the cold on the enzymatic and non-enzymatic processes inside the cells. This damage is associated with oxidative stress and lipid peroxidation, which can lead to cell degeneration/apoptosis. During the cooling period, the transitions of the lipid phase lead to a disorganization and extravasation of the cell membrane, affecting cell viability (Godoy et al., 2012). Other damage caused by the cold is the denaturation of proteins due to temperature variation (Lattman et al., 1994). As the structure of water molecules and hydrogen bonds become more ordered by exposure to low temperature, it is believed that the hydrophobic bonds between the side protein chains are loosened and, consequently, the conformation of the protein molecules changes resulting in denaturation (Tajima \& Shimizu, 1973). Alternatively, induction by oxidative stress may lead to the production of reactive oxygen types, causing protein denaturation, lipid peroxidation and cellular apoptosis (Wood \& Youle, 1995; Prasad, 1996).

A large amount of mitochondria with altered volume and ridges was also observed in cells of the intestinal epithelium of larvae from the $18 \mathrm{~h}$ treatment. Studies in animals and plants show that the mitochondria of the cells become highly permeable and swollen after tissue samples are submitted to low temperatures (Rauen et al., 1999). Cold shock can cause cells to lose intracellular $\mathrm{K}^{+}$and become permeable to substances that otherwise would be impermeable (Godoy et al., 2012).
Genotype sex is established at the time of fertilization of the ovum by the spermatozoid, but the differentiation of phenotypic sex only occurs in later stages of development (De Bem, et al., 2012). Because fish are pecilothermic, they are greatly influenced by temperature in their gonadal differentiation. There are several studies exploring temperature for sexual reversal in fish (Ferraz \& Cerqueira, 2010; Zanardi et al., 2011). In addition to temperature, other environmental factors, such as dissolved oxygen and growth rates, may also influence the sex ratio in zebrafish.

The gonadal cord in D. rerio is formed at different times in the larvae from the control (2PHD), and $6 \mathrm{~h}$ (4PHD) and $18 \mathrm{~h}$ (6PHD) treatments. Zebrafish, under captivity conditions, commonly reach sexual maturity between 3-6 months post-fertilization. However, it is more appropriate to relate reproductive maturity to size than to age, as sexual maturity varies considerably with environmental conditions, including population density, temperature, and food availability. A standard size of approximately $23 \mathrm{~mm}$ corresponds to the reproductive maturity of this species (Dammski et al., 2011). When cryopreserved animals of the same body size were compared with control animals, the latter had well formed gonads, whereas, in cryopreserved animals, the gonads were still undifferentiated for unknown reasons.

Considering the cryopreservation of zebrafish embryos, under the conditions of this experiment, $6 \mathrm{~h}$ of storage was the one that presented the best performance in both growth and deformities.

\section{Acknowledgements}

The authors would like to thank the Aquaculture Centre of UNESP for providing the animals and the facilities; Mr Edmar Delega for his help in processing the histological material; Ms Maria Tereza P. Maglia, Mr José A. Maulin and University of São Paulo, USP, in Ribeirão Preto, Brazil for helping with transmission electron microscopy (TEM).

\section{Financial support}

This work was supported by the São Paulo Research Foundation - FAPESP (grant number 2012/24909-5).

\section{Ethical standards}

The authors assert that all procedures contributing to this work comply with the ethical standards of the relevant national and institutional guides on the care and use of laboratory animals. 


\section{References}

Ahammad, M.M., Bhattacharyya, D. \& Jana, B.B. (2003). Hatching of common carp (Cyprinus carpio L.) embryos stored at 4 and $-2^{\circ} \mathrm{C}$ in different concentrations of methanol and sucrose. Theriogenology 60, 1409-22.

Campbell, T.W. (2004). Hematology of Fish. In M.A. Thrall (ed.) Veterinary Hematology and Clinical Chemistry. Lippincott Williams \& Wilkins, pp. 277-89.

Coelho, E.B. (2014). Mechanisms of Edema Formation. Medical symposium: Semiology, Ribeirão Preto, 37, 189-98.

Costa, J.M. (2015). Phosphorus levels in diets for zebrafish Danio rerio. Thesis (doctorate in Animal Science), 89 pp. São Paulo State University - UNESP: Botucatu, 2015.

Dammski, A.P., Muller, B.R., Gaya, C. \& Regonato, D. (2011). Zebrafish - Manual of Breeding in Captivity. Federal University of Paraná, Curitiba, 107 pp.

De Bem, J.C., Fontanetti, C.S., Senhorini, J.A. \& PariseMaltempi, P.P. (2012). Effectiveness of estradiol valerate on sex inversion in Astyanax altiparanae (Characiformes, Characidae). Braz. Archives Biol. Technol. 55, 283-90.

Desai, K., Spikings, E. \& Zhang, T. (2011). Effect of chilling on sox2, sox3 and sox19a gene expression in zebrafish (Danio rerio) embryos. Cryobiology 2, 96-103.

Desai, K., Spikings, E. \& Zhang, T. (2015). Short-term chilled storage of zebrafish (Danio rerio) embryos in cryoprotectant as an alternative to cryopreservation. Fish Haus 12, 11-115.

Digmayer, M. (2010). Viability of pacu embryos, Piaractus mesopotamicus (Holmberg, 1887), submitted to $-8^{\circ} \mathrm{C}$ and different concentrations of cryoprotectants. Dissertation (Master's Degree in Animal Science), 69 pp. Maringá State University - UEM: Maringá.

Elonen, G.E., Spehar, R.L., Holcombe, G.W., Johnson, R.D., Fernandez, J.D., Erickson, R.J., Tietze, J.E. \& Cook, P.M. (1998). Comparative toxicity of 2,3,7,8-tetrachlorodibenzo$p$-dioxin to seven freshwater fish species during early life stage development. Environ. Toxicol. Chem. 17, 472.

Fernandes, K.A. (2016). Acute effects and morphological changes in larvae of Astyanax altiparanae (Garutti \& Britski, 2000) (Teleostei, Characidae) exposed to extracts of cyanobacteria producing and not producing microcystinLR. Dissertation (Master in Environment and Water Resources) 52 pp. Federal University of Itajubá - UNIFEI: Itajubá.

Ferraz, E.M. \& Cerqueira, V.R. (2010). Influence of temperature on gonadal maturation of sea bass, Centropomus undecimalis. Bol. Inst. Pesca 36, 73-83.

Fornari, D.C., Ribeiro, R.P., Streit, D.P. Jr., Vargas, L., Godoy, L.C., Oliveira, D., Digmayer, M., Galo, J.M. \& Neves, P.R. (2012). Increasing storage capability of pacu (Piaractus mesopotamicus) embryos by chilling: Development of a useful methodology for hatcheries management. CryoLetters 33, 126-34.

Godoy, L.C., Zampolla, T., Streit, D. Jr., Bos-Mikich, A. \& Zhang, T. (2012). Vitrification of zebrafish (Danio rerio) ovarian follicles. Cryobiology 65, 3, 344.

Goltermann, H.L., Clymo, R.S. \& Ohnstad, M.A.M. (1978). Methods for Physical and Chemical Analysis of Freshwaters. London: Blackwell Science Publication, IBP Handbook Number 8, 214 pp.
Kimmel, C.B., Ballard, W.W., Kimmel, S.R., Ullmann, B. \& Schilling, T.F. (1995). Stages of embryonic development of the zebrafísh. Dev. Dynam. 203, 253-310.

Lattman, E.E., Fiebig, K.M. \& Dill, K.A. (1994). Modelling compact denatured states of proteins. Biochemistry 33, 6158-66.

Leatherland, J.F. \& Woo, P.T. (eds). (1998) Fish Diseases NonInfectious Disorders. CABI, 2, 379 pp.

Leme dos Santos, H.S. \& Azoubel, R. (1996). Comparative Embryology. FUNEP, Jaboticabal, 189 pp.

Little, E.E., Fairchild, J.F. \& De Lonay, A.J. (1993). Behavioral methods for assessing impacts of contaminants on early life stage fishes. Am. Fish. Soc. Symp. 14, $67-76$.

Lopes, T.S., Strei, D. Jr., Ribeiro, R.P. \& Romagosa, E. (2014). Post-cooling damage to Piaractus mesopotamicus embryos at different stages of development. Atas de Saúde Amb. 2, $1-11$.

Miliorini, A.B., Murgas, L.D.S., Viveiros, A.T.M., Franciscatto, R.T., Silva, M.O.B. \& Maria, A.N. (2002). Cooling of pacu semen (Piaractus mesopotamicus) at $4^{\circ} \mathrm{C}$ using different concentrations of dimethylsulfoxide. Rev. Bras. Reprod. Anim. 26, 209-11.

Morris, G.J. \& Watson, P.F. (1984). Cold shock injury - a comprehensive bibliography. Cryo-Lett. 5, 352-72.

Nagamatsu, P.C. (2013). Effects of neurotoxic metals on Rhamdia quelen larvae exposed in early stages of development. Dissertation (Master's Degree in Cellular and Molecular Biology), 85 pp. Federal University of Paraná - UFPR: Curitiba.

Nakatani, K., Agostinho, A.A. \& Baumgartner, G. (2001). Freshwater Fish Eggs and Larvae: Development and Identification Manual. Nupélia, Maringá, 359 pp.

Neves, P.R., Ribeiro, R.P., Streit, D.P. Jr., Natali, M.R., Fornari, D.C., Santos, A.I. \& Godoy, L.C. (2014). Injuries in pacu embryos (Piaractus mesopotamicus) after freezing and thawing. Zygote 22, 25-31.

Ninhaus-Silveira, A., Foresti, F., Azevedo, A. et al. (2008). Cryogenic preservation of embryos of Prochilodus lineatus (Valenciennes, 1836) (Characiforme; Prochilodontidae). Zygote 17, 45-55.

Paes, M.C.F., Silva, R.C., Nascimento, N.F., Valentin, F.N., Senhorini, J.A. \& Nakaghi, L.S.O. (2014). Hatching, survival and deformities of piracanjuba (Brycon orbignyanus) embryos subjected to different cooling protocols. Cryobio$\log y$ 69, 451-6.

Pinder, A.C. \& Gozlan, R.E. (2004). Early ontogeny of sunbleak. J. Fish Biol. 64, 762-75.

Prasad, T.K. (1996). Mechanisms of chilling-induced oxidative stress injury and tolerance in developing maize seedlings: changes in antioxidant system, oxidation of proteins and lipids, and protease activities. Plant J. 10, 1017-26.

Rall, W.F. (1993). Recent advances in the cryopreservation of salmonid fishes. In Genetic Conservation of Salmonid Fishes (J.G. Cloud \& G.H. Thorgaard, eds), Plenum, New York pp. 137-58.

Rauen, U., Polzar, B., Stephan, H., Mannherz, H.G. \& De Groot, H. (1999). Could induced apoptosis in cultured hepatocytes and liver endothelial cells: 
mediation by reactive oxygen species. FASEB J. 13, 11568.

Rawson, D. \& Zhang, T. (2005). New approaches to the cryopreservation of fish oocytes and embryos. The role of biotechnology. Villa Gualino, Turin, Italy - 5-7 March, pp. 209-10.

Sakamoto, S. \& Yone, Y. (1978). Effect of starvation on hematological characteristics, and the contents of chemical components and activities of enzymes in blood serum of red sea bream. J. Fac. Agric. Kyushu Univ. 23, 63-9.

Stevanato, D.J. (2016). Larval and post-larval ontogeny of Astyanax altiparanae (Garutti \& Britski, 2000) in laboratory. Dissertation (Masters in Animal Science) 79 pp. Federal University of Paraná - UFPR: Curitiba.

Tajima, K. \& Shimizu, N. (1973). Effect of sterol, alcohol and dimethyl-sulfoxide on sorghum seedling damaged by above-freezing low temperature. Proc. Crop. Sci. Soc. Jpn. 42, 220-6.

Tolosa, E.M.C., Rodrigues, C.J., Behmer, O.A. \& Freitas-Neto, A.G. (2003). Manual of Techniques for Normal and Pathological Histology. Manole, Barueri, 341 pp.

Walker, M. K. \& Peterson, R.E. (1991). Potencies of polychlorinated dibenzo- $p$-dioxin, dibenzofuran, and biphenyl congeners, relative to 2,3,7,8-tetrachlorodibenzo- $p$-dioxin, for producing early life stage mortality in rainbow trout (Oncorhynchus mykiss). Aquat. Toxicol. 21, 219-37.

Wood, K.A. \& Youle, R.J. (1995). The role of free radicals and p53 in neuron apoptosis in vivo. J. Neurosci. 15, 8, 5851-7.

Zanardi, M.F., Dias-Koberstein, T.C.R, Dos Santos, M.A. \& Malheiros, E.B. (2011). Productive performance and sexual reversal in tilapia in two hormonal methods. Vet. Zootec. $18,24-36$. 